\title{
Intra-individual variation in RMR in older people
}

\author{
Megan R. D. Gibbons ${ }^{1}$, C. Jeya K. Henry ${ }^{1 *}$, Stanley J. Ulijaszek ${ }^{2}$ and Helen J. Lightowler ${ }^{1}$ \\ ${ }^{1}$ Nutrition and Food Science Group, School of Biological and Molecular Sciences, Oxford Brookes University, \\ Gipsy Lane Campus, Headington, Oxford OX3 OBP, UK \\ ${ }^{2}$ Institute of Social and Cultural Anthropology, University of Oxford, 51 Banbury Road, Oxford OX2 6PF, UK
}

(Received 31 January 2003 - Revised 28 October 2003 - Accepted 14 November 2003)

\begin{abstract}
In the factorial estimation of total energy expenditure it is assumed that the intra-individual variation in RMR is small. Little is known about the intra-individual variation in RMR in older subjects. The present study investigated the intra-individual variation in RMR in older people. Measurements of RMR were made in twenty-seven older subjects, mean age 71.6 (SD 6.1) years, on two separate occasions (T1 and T2) and on a third occasion (T3) in nineteen of the subjects. Measurements of height and weight were taken in all subjects. RMR measurements were made in the laboratory using a Deltatrac ${ }^{\mathrm{TM}}$ (ventilated-hood indirect calorimeter; Datex, Helsinki, Finland). All subjects had fasted overnight for $12 \mathrm{~h}$ and refrained from strenuous exercise before measurements. The intra-individual CV in RMR (kJ/d) after T1 and T2 was $2.5 \%$ in women and $3.6 \%$ in men and was $2.6 \%$ in women and $3.4 \%$ in men after all three sets of measurements. Although mean RMR did not vary across T1, T2 and T3, there was significant 'crossing tracks' across the three measurement occasions in some individuals, reflecting a high degree of within-subject variability. The methods used had a significant measurement error associated with them (high $R$ value; significant $F$ ratio in three-way ANOVA). In conclusion, the results from the present study indicate that intraindividual variation in RMR was low in older people. The intra-individual variation in the elderly is similar to that seen in younger age groups.
\end{abstract}

Older people: Resting metabolic rate: Deltatrac ${ }^{\mathrm{TM}}$ : Reproducibility

People aged $>60$ years represent an increasing proportion of the population. In the UK, the number of people aged $>60$ years increased from about 9.1 million in 1971 to $10 \cdot 7$ million in 2000 (Office for National Statistics, 2002). This represents an increase from approximately 16 to $18 \%$ of the population.

RMR has become an increasingly important measurement in determining energy requirements of individuals and populations. RMR represents the largest component of daily energy expenditure (approximately 60-75\%), followed by physical activity (approximately 15-30\%) and diet-induced thermogenesis (approximately 10\%). It has been widely documented that RMR decreases with age, mainly due to a decrease in lean body mass and an increase in body fat (Piers et al. 1998; Elia et al. 2000). Generally, levels of physical activity are lower in older people; therefore measurements of RMR assume greater significance in predicting the energy requirements of older people.

There is currently some uncertainty in accurately predicting daily energy requirements of older people (Goran \& Poehlman, 1992). This is largely due to the paucity of data on energy estimates and RMR for this age group. For instance, the Food and Agriculture Organization/ World Health Organization/United Nations University (1985) equations for predicting BMR in older men and women are based on sample sizes of only fifty and thirty-eight subjects respectively. This is a small sample size on which to make assumptions about the general population. Moreover, little is known about the intra-individual variation in RMR in older subjects. In the factorial estimation of total energy expenditure it is assumed that the intra-individual variation in RMR is small. Indeed several reports (Henry et al. 1989; Shetty et al. 1996) confirm a very small CV in young men over a period of weeks, months and years. Remarkably, there is little information on the intra-individual variation in RMR in the 'older elderly' ( $>75$ years old). Given the increasing prevalence of disease and ill-health in this age group, the intra-individual variation in RMR may be much greater in older people. Assessing and quantifying the intra-individual variation in RMR is important in the factorial estimation of total energy expenditure in older people. The aim of the present study was to determine the technical error of measurement (TEM) and intra-individual variation in RMR in older people.

\section{Methods}

Subjects

Twenty-seven older subjects, mean age 71.6 (SD 6.1) years, participated in the main part of the study. The subjects 
were seven men (mean age $75 \cdot 1$ (SD 7.0) years) and twenty women (mean age 70.3 (SD 5.3) years). Nineteen subjects (six men (mean age 74.1 (SD 6.8) years) and thirteen women (mean age 69.7 (SD 4.4) years)) agreed to have a third measurement of RMR. All subjects were white nonsmokers and the female subjects were postmenopausal; thus, the effects of race (Henry \& Rees, 1991), nicotine (Dalloso \& James, 1984) and menstrual cycle (Curtis et al. 1996; Henry et al. 2003) on RMR were excluded. Although the subjects were healthy, some were taking medication during the study period. Subjects were recruited through posters placed in libraries, supermarkets and general practitioners' surgeries, and through a mailshot. Eligibility criteria for the study included being able to give informed consent and being aged $>60$ years. The study was approved by the Research Ethics Officer for the School of Biological and Molecular Sciences at Oxford Brookes University.

\section{Measurement protocol}

All measurements of RMR were made in the laboratory. RMR was measured using a Deltatrac ${ }^{\mathrm{TM}}$ (ventilated-hood indirect calorimeter; Datex, Helsinki, Finland). RMR was determined by measuring $\mathrm{O}_{2}$ consumption and $\mathrm{CO}_{2}$ production. The Deltatrac ${ }^{\text {TM }}$ was calibrated before each use with Quick $\mathrm{Cal}^{\mathrm{TM}}$ calibration gas to $5 \% \mathrm{CO}_{2}$ and $95 \%$ $\mathrm{O}_{2}$. Ethanol checks were performed every 3-6 months.

All measurements were made by the same trained investigator (M. R. D. G.). Subjects were asked to fast overnight for $12 \mathrm{~h}$ and to refrain from strenuous exercise before measurements. Room temperature was maintained at $22-24^{\circ} \mathrm{C}$; subjects were asked to rest in the supine position, to minimize movements and to remain awake during the measurement period. Subjects remained under the ventilated hood for a total of $40 \mathrm{~min}$; the first $10 \mathrm{~min}$ of readings were excluded as this was taken as the 'settling-in period'. RMR was taken as an average of the readings during the remaining 30 min measurement period. RMR measurements were taken on two separate occasions (T1 and T2) within 1 month of the first measurement in the main part of the study. A third measurement (T3) of RMR was made on nineteen of the twenty-seven subjects. This was completed within 1 month of the T2 measurement.

Measurements were also taken of height (portable digital stadiometer; Soehnle, Murhardt, Germany) and weight (digital weighing scales, accurate to $100 \mathrm{~g}$; Terraillon, chatou Cedex, France) in all subjects. Measurements for height and weight were taken according to Lohman et al. (1991). BMI was calculated as weight $(\mathrm{kg}) /$ height $(\mathrm{m})^{2}$. All measurements were taken in triplicate.

\section{Statistical analyses}

Statistical analyses were performed using SPSS 10.0 (1999; SPSS Inc., Chicago, IL, USA). Results are expressed as mean values and standard deviations unless stated otherwise. Before statistical analysis, the normality of the data was tested using the Shapiro-Wilks statistic; all data were normally distributed. Comparisons within groups were undertaken using paired $t$ tests and between groups using independent sample $t$ tests. Anthropometric data were compared with results from the National Diet and Nutrition survey (Finch et al. 1998) using one-sample $t$ tests. Statistical significance was set at $P<0.05$.

The TEM and coefficient of reliability $(R)$ were determined using equations given by Ulijaszek \& Kerr (1999):

$$
\mathrm{TEM}=\sqrt{\left(\left(\Sigma \mathrm{D}^{2}\right) / 2 n\right)}
$$

and

$$
R=1-\left((\text { total } \mathrm{TEM})^{2} / \mathrm{sD}^{2}\right),
$$

where $\mathrm{D}$ is the difference between measurements and $n$ is the number of subjects measured.

Replicate measures of RMR were not taken in the present study. In their absence, TEM and CV (\%) values reflect total intra-individual variation. There are two components to intra-individual variation in RMR: measurement error and true physiological variation in RMR. These are difficult to separate, the usual way being the use of replicate measurements. In the present study, approximations of replicate measures were obtained by treating each 30 min RMR measure as two 15 min replicates, using missing values for those subjects without a third measurement. The significance of between-subject, between-measurement and between-replicate RMR values was then assessed using a three-way (model II) ANOVA (Sokal \& Rohlf, 1969), in the manner used to determine variation in energy intake by Soares et al. (1989a).

\section{Results}

The results from Tables 1 and 2 confirmed previous studies showing that men have a higher absolute RMR than women (5903 (SD 634) v. 5344 (SD 511) kJ/d respectively) (Arciero et al. 1993; Buchholz et al. 2001). The TEM for all twenty-seven subjects was $282 \mathrm{~kJ}(R 0 \cdot 80)$ and for the nineteen subjects measured on three occasions was $239 \mathrm{~kJ}$ ( $R 0.83)$.

There was a slight decrease in the mean RMR in both male and female subjects between $\mathrm{T} 1$ and $\mathrm{T} 2$ and an increase for $\mathrm{T} 3$. The $\mathrm{CV}$ after $\mathrm{T} 1$ and $\mathrm{T} 2$ of the male $(3.6 \%)$ and female $(2.5 \%)$ subjects was low and indicated a highly reproducible method of measuring RMR. The CV after all three measurements was comparable with measurements made for $\mathrm{T} 1$ and $\mathrm{T} 2$ for male $(4.0 \%)$ and female $(3.0 \%)$ subjects. There was a decrease in mean body weight in both female $(0.5 \mathrm{~kg}, P=0.024)$ and male $(0.8 \mathrm{~kg}, P=0.355)$ subjects between T1 and T2. To account for this, RMR was also expressed as $\mathrm{kJ} / \mathrm{kg}$ per $\mathrm{d}(\mathrm{CV} 2.4 \%$ for women, $3.8 \%$ for men), but the results were still similar to $\mathrm{RMR}$ values expressed as $\mathrm{kJ} / \mathrm{d}$.

Table 3 presents results of the three-way ANOVA, showing significant differences between subjects $(P<0.001)$ and between replicates of measurement $(P<0.05)$, as well as a significant interaction between subjects and the time of measurement (T1, T2, T3). Thus, while there were no significant differences in RMR across times of measurement, measurement error was a significant component of total variation, as reflected in the low value of $R(0.83)$ (Ulijaszek \& Lourie, 1994). 
Table 1. Intra-individual variation in RMR in male subjects $(n 7) \dagger$

\begin{tabular}{|c|c|c|c|c|c|c|c|}
\hline \multirow{2}{*}{$\begin{array}{l}\text { Measurement occasion... } \\
\text { Subject }\end{array}$} & \multicolumn{5}{|c|}{$\mathrm{RMR}(\mathrm{kJ} / \mathrm{d})$} & \multicolumn{2}{|c|}{ CV (\%) } \\
\hline & T1 & T2 & T3 & Mean T1, T2 & Mean T1, T2, T3 & T1, T2 & $\mathrm{T} 1, \mathrm{~T} 2, \mathrm{~T} 3$ \\
\hline 1 & 6218 & 5947 & 6068 & 6083 & 6078 & $3 \cdot 2$ & $2 \cdot 2$ \\
\hline 2 & 7176 & 6716 & 6051 & 6946 & 6648 & 4.7 & 8.5 \\
\hline 3 & 6138 & 6447 & 6200 & 6292 & 6262 & 3.5 & $2 \cdot 6$ \\
\hline 4 & 5947 & 5678 & 5710 & 5812 & 5778 & 3.3 & 2.5 \\
\hline 5 & 5257 & 5324 & 5206 & 5290 & 5262 & 0.9 & $1 \cdot 1$ \\
\hline 6 & 4895 & 4888 & - & 4891 & 4891 & 0.1 & - \\
\hline 7 & 6832 & 5938 & 6446 & 6385 & 6405 & 9.9 & 7.0 \\
\hline $\begin{array}{l}\text { Mean } \\
\text { SD }\end{array}$ & $\begin{array}{c}6066^{*} \\
805\end{array}$ & $\begin{array}{c}5848^{*} \\
627\end{array}$ & $\begin{array}{r}5947 \\
435\end{array}$ & $\begin{array}{c}5957^{*} \\
694\end{array}$ & $\begin{array}{c}5903^{*} \\
634\end{array}$ & $3 \cdot 6$ & $4 \cdot 0$ \\
\hline
\end{tabular}

Mean values were significantly different from those of female subjects (see Table 2): ${ }^{*} P<0.05$.

†For details of subjects and procedures, see pp. 485-486.

Table 2. Intra-individual variation in RMR in female subjects ( $n$ 20)†

\begin{tabular}{|c|c|c|c|c|c|c|c|}
\hline \multirow{2}{*}{$\begin{array}{l}\text { Measurement occasion... } \\
\text { Subject }\end{array}$} & \multicolumn{5}{|c|}{ RMR (kJ/d) } & \multicolumn{2}{|c|}{ CV (\%) } \\
\hline & T1 & T2 & T3 & Mean T1, T2 & Mean T1, T2, T3 & $\mathrm{T} 1, \mathrm{~T} 2$ & $\mathrm{~T} 1, \mathrm{~T} 2, \mathrm{~T} 3$ \\
\hline 8 & 5172 & 5274 & - & 5223 & 5223 & 1.4 & - \\
\hline 9 & 5465 & 5734 & 5642 & 5599 & 5613 & 3.4 & 2.4 \\
\hline 10 & 5603 & 5490 & 5487 & 5546 & 5526 & 1.4 & 1.2 \\
\hline 11 & 6040 & 6214 & 5916 & 6127 & 6057 & $2 \cdot 0$ & 2.5 \\
\hline 12 & 5518 & 5428 & - & 5473 & 5473 & $1 \cdot 2$ & - \\
\hline 13 & 7139 & 5622 & 6037 & 6381 & 6266 & $16 \cdot 8$ & 12.5 \\
\hline 14 & 5996 & 5363 & 5924 & 5679 & 5761 & 7.9 & 6.0 \\
\hline 15 & 5115 & 4795 & - & 4955 & 4955 & 4.6 & - \\
\hline 16 & 4874 & 4916 & 4976 & 4895 & 4922 & 0.6 & 1.0 \\
\hline 17 & 5303 & 5345 & 5342 & 5324 & 5330 & 0.6 & 0.4 \\
\hline 18 & 4665 & 4574 & - & 4620 & 4620 & 1.4 & - \\
\hline 19 & 5072 & 5072 & 5360 & 5072 & 5168 & 0.0 & $3 \cdot 2$ \\
\hline 20 & 4762 & 4775 & 4992 & 4769 & 4843 & 0.2 & $2 \cdot 7$ \\
\hline 21 & 4439 & 4505 & - & 4472 & 4472 & 1.0 & - \\
\hline 22 & 6334 & 6125 & 6408 & 6230 & 6289 & $2 \cdot 4$ & $2 \cdot 3$ \\
\hline 23 & 5499 & 5497 & 5467 & 5498 & 5488 & 0.0 & 0.3 \\
\hline 24 & 5802 & 5752 & - & 5777 & 5777 & 0.6 & - \\
\hline 25 & 5112 & 4985 & - & 5049 & 5049 & 1.8 & - \\
\hline 26 & 5059 & 5160 & 4914 & 5109 & 5044 & 1.4 & $2 \cdot 4$ \\
\hline 27 & 5012 & 4905 & 5105 & 4958 & 5007 & 1.5 & $2 \cdot 0$ \\
\hline Mean & $5399^{*}$ & $5277^{*}$ & 5505 & $5338^{*}$ & $5344^{*}$ & $2 \cdot 5$ & 3.0 \\
\hline SD & 634 & 474 & 462 & 527 & 511 & & \\
\hline
\end{tabular}

Mean values were significantly different from those of male subjects (see Table 1 ): ${ }^{*} P<0.05$.

†For details of subjects and procedures, see pp. 485-486.

Table 3. Three-way ANOVA (type II model) of RMR between three measurement occasions and between first and final 15 min of measurement $^{*}$

\begin{tabular}{|c|c|c|c|c|c|}
\hline Source & Sum of squares & df & Mean square & $F$ ratio & Statistical significance of effect: $P$ \\
\hline Between time of measurement & 63671.560 & 2 & $31835 \cdot 780$ & $2 \cdot 771$ & NS \\
\hline $\begin{array}{l}\text { Between first and final } 15 \mathrm{~min} \\
\text { of measurement }\end{array}$ & $8770 \cdot 727$ & 1 & $8770 \cdot 727$ & $5 \cdot 054$ & 0.03 \\
\hline Between subjects & $2460530 \cdot 840$ & 24 & $102522 \cdot 118$ & 8.680 & $<0.001$ \\
\hline $\begin{array}{l}\text { Time of measurement } \times \text { first and final } 15 \text { min of } \\
\text { measurement }\end{array}$ & $7900 \cdot 573$ & 2 & $3950 \cdot 287$ & $2 \cdot 797$ & NS \\
\hline Time of measurement $\times$ subjects & 551459.440 & 48 & 11488.738 & $8 \cdot 136$ & $<0.001$ \\
\hline $\begin{array}{l}\text { First and final } 15 \text { min of } \\
\text { measurement } \times \text { subjects }\end{array}$ & 41648.440 & 4 & $1735 \cdot 352$ & 1.229 & NS \\
\hline $\begin{array}{l}\text { Time of measurement } \times \text { first and final } 15 \text { min of } \\
\text { measurement } \times \text { subjects }\end{array}$ & $67781 \cdot 760$ & 48 & $1412 \cdot 120$ & & \\
\hline
\end{tabular}

${ }^{*}$ For details of subjects and procedures, see pp. $485-486$. 
Although on average RMR does not vary significantly across $\mathrm{T} 1, \mathrm{~T} 2$ and $\mathrm{T} 3$, the significant interaction term reflects a high degree of within-subject variability, in that individuals' RMR does not track across the period of measurement (Fig. 1).

Predicted BMR was calculated using equations from the Food and Agriculture Organization/World Health Organization/United Nations University (1985). The mean predicted RMR was 5632 (SD 488) kJ/d in women and 6451 (SD 725) $\mathrm{kJ} / \mathrm{d}$ in men. Compared with measured RMR values, the Food and Agriculture Organization/World Health Organization/ United Nations University (1985) equations overestimated RMR in sixteen women and six men. In women, RMR was over-estimated by 7 (SD 5) (range 2-20) \% and in men by 10 (SD 5) (range 2-18) \%.

The heights, weights and BMI of the male and female subjects are shown in Table 4. Intra-individual $\mathrm{CV}$ for body weight was 0.6 (range $0.0-2.6$ ) $\%$ in women and 1.4 (range $0 \cdot 0-2.4) \%$ in men. The mean BMI $\left(26.2 \mathrm{~kg} / \mathrm{m}^{2}\right.$ ) fell within the overweight range $\left(25 \cdot 0-29.9 \mathrm{~kg} / \mathrm{m}^{2}\right)$. Female subjects had a higher mean BMI than their male counterparts. Four male subjects were classified as normal, two as overweight and one as obese, giving a mean BMI $25.5 \mathrm{~kg} / \mathrm{m}^{2}$, which was within the overweight range. One female subject was classified as underweight, six as normal, six as overweight and seven as obese, which gave a mean BMI $26.5 \mathrm{~kg} / \mathrm{m}^{2}$ (within the overweight range). In all the subjects measurements of height, weight, BMI and grip strength were above the 50th percentile

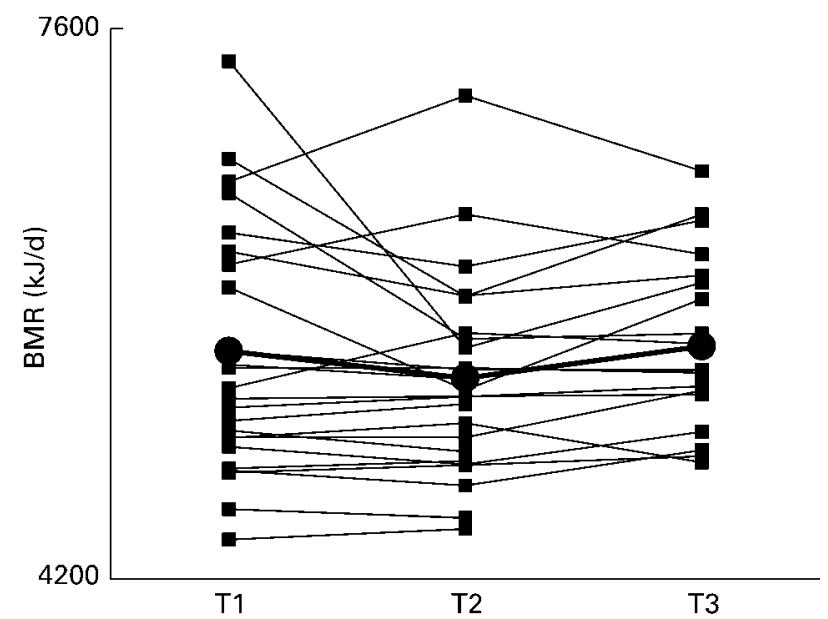

Fig. 1. Variation in individual RMR in older people. T1, T2, T3, measurement occasions. For details of subjects and procedures, see Table 4 and pp. 485-486. - - -, Mean values. (median) as measured in free-living male and female subjects of the same age group (Finch et al. 1998).

There was no significant difference $(P=0.495)$ in the RMR of medicine users $(n 16,75.0(\mathrm{SD} 8 \cdot 1) \mathrm{kJ} / \mathrm{kg}$ per d) $v$. non-medicine users ( $n$ 11, 77.1 (SD 6.8) $\mathrm{kJ} / \mathrm{kg}$ per d). This suggests that the effect of medicine on metabolic rate was minimal (Henry, 2000).

\section{Discussion}

Assessing and quantifying the intra-individual variation in RMR is important in the factorial estimation of total energy expenditure in older people. The present study indicates that intra-individual variation in RMR was low in older people. The study also confirms that the intra-individual variation in older people is similar to that seen in younger subjects. Although on average RMR did not vary across $\mathrm{T} 1$, T2, and T3, there was significant 'crossing tracks' across the three times of measurement in some individuals, reflecting a high degree of within-subject variability.

We have little information on the intra-individual variation in RMR in older people. Visser et al. (1995) repeated measurements of RMR in older subjects and had a CV of 7.8 and $6.0 \%$ in men and women respectively. These results are somewhat higher than those from the present study. A study by Reilly et al. (1993) involved taking repeated measurements of BMR in eleven healthy elderly women using a portable open-circuit indirect calorimeter. The results showed a mean difference of 2.9 (range $0.1-$ $7 \cdot 2$ ) $\%$ between the measurements, which is comparable with the findings in the present study using twenty female subjects $(2 \cdot 5$ (range $0 \cdot 0-16 \cdot 8) \%$ ).

Repeated measurements of RMR in older people appear to be reproducible using the measurement protocol outlined in the present study. However, the methods used did show a significant measurement error associated with them (high $R$ value; significant $F$ ratio in three-way ANOVA). Wells $\&$ Fuller (1998) showed that the Deltatrac ${ }^{\mathrm{TM}}$ (Datex), used in the present study, is a very precise metabolic monitor and is accurate within $3 \%$ for both gas exchange and energy expenditure. Three subjects had large CV of 9.9, 16.8 and $7.9 \%$ (no. 7,13 and 14 respectively). These large variations could be due to the subjects being in an anxious state. Other possible reasons could include not having fasted for the full $12 \mathrm{~h}$, being engaged in strenuous activity on the morning of one of the measurements or the onset of illness (Tzankoff \& Norris, 1978).

None of the subjects had prior experience of RMR measurements using a ventilated hood. Soares et al.

Table 4. Anthropometric data for all subjects*

Means values standard deviations and ranges

\begin{tabular}{|c|c|c|c|c|c|c|c|c|c|c|c|c|}
\hline & \multicolumn{3}{|c|}{ Age (years) } & \multicolumn{3}{|c|}{ Height (m) } & \multicolumn{3}{|c|}{ Weight (kg) } & \multicolumn{3}{|c|}{ BMI $\left(\mathrm{kg} / \mathrm{m}^{2}\right)$} \\
\hline & Mean & SD & Range & Mean & SD & Range & Mean & SD & Range & Mean & SD & Range \\
\hline Male & $75 \cdot 1$ & $7 \cdot 0$ & $(66 \cdot 5-82 \cdot 8)$ & 1.75 & 0.04 & $(1 \cdot 70-1 \cdot 81)$ & $78 \cdot 1$ & $12 \cdot 8$ & $(67 \cdot 7-103 \cdot 0)$ & $25 \cdot 5$ & $4 \cdot 2$ & $(21.9-34.4)$ \\
\hline Female & $70 \cdot 3$ & $5 \cdot 3$ & $(61 \cdot 8-83 \cdot 8)$ & 1.65 & 0.07 & $(1.49-1.77)$ & 71.6 & $11 \cdot 1$ & $(55 \cdot 1-91 \cdot 3)$ & 26.5 & $4 \cdot 2$ & $(18 \cdot 8-34 \cdot 3)$ \\
\hline Both & $71 \cdot 6$ & $6 \cdot 1$ & $(61 \cdot 8-82 \cdot 8)$ & 1.67 & 0.08 & $(1.49-1.81)$ & $73 \cdot 3$ & $11 \cdot 7$ & $(55 \cdot 1-103 \cdot 0)$ & $26 \cdot 2$ & $4 \cdot 2$ & $(18.8-34.4)$ \\
\hline
\end{tabular}

* For details of procedure, see pp. 485-486. 
(1989b) compared BMR measurements produced by five different machines, including a ventilated hood. He found that there were significant interactions between subjects with the ventilated hood when they were unaccustomed to the apparatus. Despite being unfamiliar with the ventilated hood, the results in our present study were reproducible.

In conclusion, the protocol outlined in the present study for measurement of RMR produced reproducible results in older people. However, it is important to ensure that subjects adhere to the protocol to minimize intra-individual variation in RMR. The intra-individual variation in RMR in the elderly was low and was similar to that seen in younger age groups. This suggests that the use of the factorial method to estimate energy requirements is also applicable in the older population.

\section{Acknowledgements}

This research was carried out as part of the pan-European Healthsense study and was funded by the Fifth Framework Programme.

\section{References}

Arciero PJ, Goran I \& Poehlman ET (1993) Resting metabolic rate is lower in women than men. J Appl Physiol 75, $2514-2520$

Buchholz AC, Rafii M \& Pencharz PB (2001) Is resting metabolic rate different between men and women? Br J Nutr 86, 641-646.

Curtis V, Henry CJK, Birch E \& Ghusain-Choueiri A (1996) Intraindividual variation in the basal metabolic rate of women: effect on the menstrual cycle. Am J Hum Biol 8, 631-639.

Dalloso HM \& James WPT (1984) The role of smoking in the regulation of energy balance. Int J Obes 8, 365-375.

Elia M, Ritz P \& Stubbs RJ (2000) Total energy expenditure in the elderly. Eur J Clin Nutr 54, S92-S103.

Finch S, Doyle W, Lowe C, Bates C, Prentice A, Smith G \& Clarke P (1998) National Diet and Nutrition Survey: People Aged 65 Years and Over - Vol. 1. London: The Stationery Office.

Food and Agriculture Organization/World Health Organization/ United Nations University (1985) Energy and Protein Requirements. Technical Report Series no. 724. Geneva: WHO.

Goran MI \& Poehlman ET (1992) Total energy expenditure and energy requirements in healthy elderly persons. Metabolism 41, 744-753.

Henry CJK (2000) Mechanisms of changes of basal metabolism during ageing. Eur J Clin Nutr 54, S77-S91.

Henry CJK, Hayter J \& Rees DG (1989) The constancy of basal metabolic rate in free-living male subjects. Eur J Clin Nutr $\mathbf{4 3}$, 727-731.

Henry CJK, Lightowler HJ \& Marchini J (2003) Intra-individual variation in resting metabolic rate during the menstrual cycle. Br J Nutr 89, 811-817.

Henry CJK \& Rees DG (1991) New predictive equations for the estimation of basal metabolic rate in tropical peoples. Eur J Clin Nutr 45, 177-185.

Lohman TG, Roche AF \& Martorell R (1991) Anthropometric Standardization Reference Manual. Champaign, IL: Human Kinetics.

Office for National Statistics (2002) Health Statistics Quarterly, No. 16. London: The Stationery Office.

Piers LS, Soares MJ, McCormack LM \& O’Dea K (1998) Is there evidence for an age-related reduction in metabolic rate? J Appl Physiol 85, 2196-2204.

Reilly JJ, Lord A, Bunker VW, Prentice AM, Coward WA, Thomas AJ \& Briggs RS (1993) Energy balance in healthy elderly women. Br J Nutr 69, 21-27.

Shetty PS, Henry CJK, Black AE \& Prentice AM (1996) Energy requirements of adults: an update on basal metabolic rates (BMRs) and physical activity levels (PALs). Eur J Clin Nutr 50, S11-S23.

Soares MJ, Piers LS, Kraai L \& Shetty PS (1989a) Day-to-day variations in basal metabolic rates and energy intakes of human subjects. Eur J Clin Nutr 43, 465-472.

Soares MJ, Sheela ML, Kurpad AV \& Kulkarni RN (1989b) The influence of different methods on basal metabolic rate measurements in human subjects. Am J Clin Nutr 50, $731-736$.

Sokal RR \& Rohlf FJ (1969) Biometry: Principles and Practice of Statistics in Biological Research. New York: WH Freeman.

Tzankoff SP \& Norris AH (1978) Longitudinal changes in basal metabolism in man. $J$ Appl Physiol 45, 536-539.

Ulijaszek SJ \& Kerr DA (1999) Anthropometric measurement error and the assessment of nutritional status. Am J Clin Nutr 82, $165-177$.

Ulijaszek SJ \& Lourie JA (1994) Intra- and inter-observer error in anthropometric measurement. In Anthropometry: The Individual and the Population, pp. 30-55 [SJ Ulijaszek and CGN Mascie-Taylor, editors]. Cambridge: Cambridge University Press.

Visser M, Deurenberg P, Vanstaveren WA \& Hautvast J (1995) Resting metabolic rate and diet-induced thermogenesis in young and elderly subjects - relationship with body-composition, fat distribution, and physical-activity level. Am J Clin Nutr 61, 772-778.

Wells JCK \& Fuller NJ (1998) Precision and accuracy in a metabolic monitor for indirect calorimetry. Eur J Clin Nutr 52, $536-540$. 